\title{
Sensitivity and Specificity of Lateral Flow Antigen Test Kits for COVID-19 in Asymptomatic Population of Quarantine Centre of
} Province 3 Shrestha $B,{ }^{1}$ Neupane $A K,{ }^{1}$ Pant $S,{ }^{2}$ Shrestha $A,{ }^{3}$ Bastola $A,{ }^{4}$ Rajbhandari $B,{ }^{5}$ Thapa $A,{ }^{6}$ Singh $A{ }^{1}$

${ }^{1}$ Nepalese Army Institute of Health Sciences, Kathmandu, Nepal.

${ }^{2}$ Nepal Health Research Council, Kathmandu, Nepal.

${ }^{3}$ Patan Academy of Health Science, Lalitpur, Patan, Nepal.

${ }^{4}$ Shukraraaj Tropical and Infectious Disease Hospital, Kathmandu, Nepal.

${ }^{5}$ Nepal Police Hospital, Kathmandu, Nepal.

${ }^{6}$ Nepal Armed Police Force Hospital, Kathmandu, Nepal.

\section{Corresponding Author}

Suman Pant

Nepal Health Research Council,

Kathmandu, Nepal.

E-mail: suman.p@fph.tu.ac.th

\section{Citation}

Shrestha B, Neupane AK, Pant S, Shrestha A, Bastola A, Rajbhandari B, et al. Sensitivity and Specificity of Lateral Flow Antigen Test Kits for COVID-19 in Asymptomatic Population of Quarantine Centre of Province 3. Kathmandu Univ Med J. 2020;COVID-19 Special Issue 70(2):36-9.

\begin{abstract}
\section{Background}

Nearly after 6 months of the spread of Corona Virus Disease 19, along with the world Nepal is still trying to control the spread and prevent general population from acquiring it. With limited resources in manpower, technology and evidence it has been a difficult battle. But with time and more understanding of the virus new technology to detect the virus are coming up. It is a major breakthrough in the diagnostic field as this helps us in not only detecting the virus but also helps us to mobilize our human resources. This comes in a time where the cases are increasing at an alarming rate. Although numbers of Polymerase Chain Reaction testing have increased but due to the time consuming and the cost wise, we need a faster and equally reliable alternative. Antigen test approved by different countries can be used for point of care, screening and surveillance depending upon the requirements after calculating its sensitivity, specificity and accuracy.
\end{abstract}

\section{Objective}

To find out sensitivity and specificity of the Antigen test kit for COVID-19.

\section{Method}

Antigen tests were compared with Reverse Transcription Polymerase Chain Reaction as a reference standard in calculated sample size of 113 subjects in a high risk population. Both Reverse Transcription Polymerase Chain Reaction and antigen test were performed in a same subject with in maximum of 2 days' interval. Convenience sampling technique was used to select the subjects. Ethical approval was taken from Nepal Health Research Council before data collection. Study was done from August to September 2020 from Quarantine center of Province 3.

\section{Result}

There were total of 113 test carried out, among those 47 were positive and 66 were negative in Reverse Transcription Polymerase Chain Reaction. After preparing two by two table, Sensitivity and specificity of the tested was calculated which came out to be $85 \%$ and $100 \%$ respectively, with accuracy of $93.80 \%$.

\section{Conclusion}

Even though the sensitivity and specificity came to be higher, this test should be interpreted cautiously depending upon the prevalence of Corona Virus Disease 19 in that particular community and the clinical and epidemiological context of the person who has been tested. When in doubt by clinical correlation should be confirmed with Reverse Transcription Polymerase Chain Reaction.

\section{KEY WORDS}

Asymptomatic, Coronavirus Disease 19, Lateral flow antigen test, Sensitivity 


\section{INTRODUCTION}

In Wuhan city, a new form of viral infection emerged, now referred to as Severe acute respiratory syndrome coronavirus 2 (SARS-CoV-2). Cases of SARS-CoV-2 have been recorded in more than 210 countries. ${ }^{1}$ Globally there have been $30,055,710$ confirmed cases of Corona Virus Disease 19 (COVID-19). ${ }^{2}$ Nepal detected its first case in January 2020 since then there has been a surge in the cases leading to 65,593 confirmed cases nationwide. ${ }^{3,4}$ Testing early and detecting the virus and isolating them from the community is equally essential. ${ }^{5}$

Polymerase Chain Reaction (PCR) is the standard testing for COVID-19, it still struggles to reach the rural and remote parts of the country, and it lags behind due to its timeconsuming process. A rapid device to facilitate testing outside of laboratory is now necessary. We need a faster and equally reliable alternative. Another advantage of antigen test is its affordability. Objective of this study was to find out sensitivity and specificity of the antigen test kit for COVID-19.

\section{METHODS}

An observational diagnostic study was conducted among 113 study subjects who were close contacts of confirmed cases identified through contact tracing residing in quarantine center from August 2020 to September 2020. Ethical Approval letter was obtained from Nepal Health Research Council (Ref No. 2868). On the $5^{\text {th }}$ day of quarantine two nasopharyngeal swabs was collected from same individual by trained lab technician. One of the samples was transported in $3 \mathrm{ml}$ Viral Transport Medium (VTM) and sent to molecular lab for RT-PCR test and other sample from the same individual was processed for the results as instructed by the manufacturing company of antigen kit. At the time of swab collection none of the individuals were symptomatic. Consent was obtained from the participants. Data collection was done from province 3 quarantine, collection was done with the help of nasopharyngeal secretion, both sample for RT-PCR and Antigen RDT. For the detail procedures of nasopharyngeal swab collection, preservation, transportation, performing RT-PCR and antigen RDT, we followed the standard protocol regulated by WHO, instruction manual of company and as per NHTC training regarding sample collection and transport. One hundred and thirteen study subjects were selected using convenient sampling technique. Nasopharyngeal swabs were collected and assay performed following the instructions recommended by the manufacturer (fig. 1).

Results of RDT as the reference method were compared with those of RT-PCR. Tests were repeated for samples with indistinct outcomes. The demographic and clinical data were obtained and analyzed in an anonymous manner from the national contact tracing forms $\mathrm{A}$ and $\mathrm{B}$. The statistical

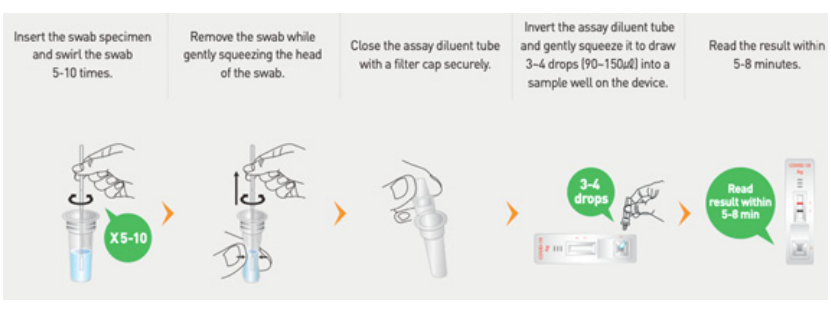

Figure 1. Detailed assay procedure. ${ }^{6}$

analysis considered sensitivity, specificity, PPV, NPV and accuracy. Data collected were entered and analyzed using MS Excel.

\section{RESULTS}

Out of 113 asymptomatic participants, 24 were females and 89 males. Participants' age ranged from 13 to 74 years. We found out, among 47 RT-PCR positive cases tested, 7 were negative, 2 weak positive and 40 were Strong positive in Antigen test (Table 1). Those negative cases found had CT value of more than 33, whereas two weak positive cases had CT at the range of 31 .

Table 1. Sensitivity, specificity, true positive, false positive, true negative and false negative results of the diagnostic test.

\begin{tabular}{|llll|}
\hline & PCR (Positive) & PCR (Negative) & Total \\
\hline Antigen (Positive) & 40 (TP) & 0 (FP) & 40 \\
\hline Antigen (Negative) & 7 (FN) & $66($ TN) & 73 \\
\hline Total & 47 & 66 & 113 \\
\hline
\end{tabular}

Our result showed $85 \%$ sensitivity, $100 \%$ specificity, $100 \%$ positive predicted value, $100 \%$ Negative predicted value, and $93.80 \%$ accuracy.

\section{DISCUSSION}

Sensitivity ranged greatly throughout research studies (from 0 to $94 \%$ ): $56.2 \%$ was the average sensitivity $(95 \% \mathrm{Cl}$ 29.5 to $79.8 \%$ ) and $99.5 \%$ was the average specificity (95\% $\mathrm{Cl} 98.1 \%$ to $99.9 \%$; based on 8 assessments on 943 samples in 5 studies). However, our study shows sensitivity of $85 \%$ and specificity of $100 \%$ with BIOCREDIT. ${ }^{7}$

Hardly any test gives a $100 \%$ accurate result; tests need to be tested, preferably by comparison with a "gold standard," to assess their accuracy. The absence of such a consistent "gold standard" for COVID-19 testing makes it difficult to evaluate the accuracy of the test. Nevertheless, in comparison with RT-PCR as standard test, accuracy of the given antigen test came out to be $92.80 \%{ }^{8}$

In this study we took RT-PCR of the asymptomatic COVID-19 cases as the gold standard test to compare with but in real absence of a clear-cut "gold standard" is a difficult task for assessing COVID-19 tests; idealistically, clinical judgment could be the best available "gold standard" based on repeat swabs, history, and contact cases known to have SARS-CoV2, chest X-rays, and chest CT. ${ }^{9}$ 
The performance of the tests depends on a number of factors, such as the time since the onset of the disease, the concentration of the virus in the sample, the quality of the sample collected from the individual and how it is analyzed, and the exact specification of the reagents in the test kits. The sensitivity of these tests could be expected to vary from $34 \%$ to $80 \%$ depending on knowledge with antigen-based RDTs for other respiratory diseases such as influenza, in which affected patients have comparable influenza virus concentrations in respiratory samples as seen in COVID-19. ${ }^{10}$

Study done by Wang et al found out sensitivity of RT-PCR in 205 patients varied, at 93\% for broncho-alveolar lavage, $72 \%$ for sputum, $63 \%$ for nasal swabs, and only $32 \%$ for throat swabs. Here in our study we took nasopharyngeal swab which shows sensitivity of $85 \%$ and specificity of $100 \%$ in comparison to that of RT-PCR. ${ }^{11}$

A study from China (with the manufacturer's participation) found an overall sensitivity of $68 \%$; however, the sensitivity increased to $98 \%$ for samples with Ct values less than or equal to $30 .{ }^{12}$ This excellent rate of identification in high viral load specimens $(C T<25)$ was confirmed in this report and in our recently published study. ${ }^{13}$

With high viral load samples, the RapiGen test also demonstrated an acceptable sensitivity (84.9\%), but was much less sensitive (15.4\%) when the viral load was low. This test had a visual readout that could have led to lower sensitivity. In two European studies, another visual band assay (Respi-Strip CORIS) was recently evaluated. Overall sensitivity ranged from $50 \%$ to $57.6 \%$; however, detection rates improved for samples with high viral loads (CT < 25) reaching sensitivities of $73.9 \%$ to $82.2 \% .{ }^{14,15}$

Depending on which gene targets are used, and whether multiple gene tests are used in combination, higher sensitivities are reported. ' $E$ ' and 'ORF' were the target genes for PCR in this study. ${ }^{16,17}$

Reported accuracies are much higher in one vitro study conducted by Corman VM, which measures the performance of primers using the coronavirus cell culture. However, in this study we have taken RT-PCR as the standard test that could have reduced the accuracy which is one of the limitations of this study. ${ }^{18}$

The accuracy may also vary depending on the disease stage and the extent of viral multiplication, in this study all participants were asymptomatic which can be correlate as low viral load condition. ${ }^{19,20}$
Huge knowledge gaps identified in a study highlight the immediate need for commercialized an-tigen test comparative studies. ${ }^{21}$ A possible explanation of the variations in performance could be linked to differences in protein targets. However, only a minority of manufacturers report details regarding the detection system. ${ }^{22}$

In the procurement of simpler, scalable diagnostic tests, quality information is valuable for local decision-making. Although these tests are less sensitive than RT-PCR, when timely results are important but access to molecular testing is limited, they could be useful during pandemic situations. ${ }^{23}$

For the implementation of novel RDT-based algorithms, which are particularly important in poorer health systems and low-resource settings such as Nepal, the potential to detect early infections could be crucial. Possible frontline applications include testing based on the community. ${ }^{24}$

However, large-scale strategies need to be well designed to avoid negative effects in light of the imperfection of tests. Another application could be as an adjunct to RT-PCR to achieve quick preliminary results, e.g. for healthcare professionals, recruit police officers, mass screening, institutional management etc. ${ }^{25}$ We have used only one antigen RDT company. Comparison with another company would have definitely shed more light on antigen testing. But due to unavailability and lack of financial resources we were not able to do so. But if we can choose brand according to the availability and resource for research study, it is important to note that the CE licensing process if it is based on manufacturers' self-reporting, which does not provide high performance, and may be misused. ${ }^{26,27}$

\section{CONCLUSION}

The antigen-based RDT evaluated here showed a high sensitivity and specificity in nasopharyngeal samples obtained from study subjects who were close contacts of confirmed cases COVID-19 staying in quarantine. The assay was easy to use and provided results in a timely manner which can be utilized in hospital for triaging asymptomatic patients who needs emergency surgery along with mass screening purpose and institutional system COVID-19 management. Hence, it has the potential to become an important tool for the early diagnosis of SARS-CoV-2, particularly in situations with limited access to molecular method.

\section{REFERENCES}

1. World Health Organization. Coronavirus disease 2019 (COVID-19) situation report-114. WHO. 2020 May 13. Available from: https:// www.who.int/docs/default-source/coronaviruse/situationreports/20200513-covid-19-sitrep-114.pdf?sfvrsn=17ebbbe_4

2. World Health Organization. WHO Coronavirus Disease (COVID-19) Dashboard. WHO. 2020. Available from: https://covid19.who.int/?g clid=EAlalQobChMIt4GZxs776wIVcdOWCh1UCwzQEAAYASAAEgKyE fD_BwE

3. Ministry of Health and Population. COVID19 Nepal. 2020. Available from: https://covid19.mohp.gov.np/

4. Bastola A, Sah R, Rodriguez-Morales AJ, Lal BK, Jha R, Ojha HC, et al. The first 2019 novel coronavirus case in Nepal. The Lancet Infectious diseases. 2020;20(3):279-80.

5. BBC News. WHO head: 'Our key message is: test, test, test'. 2020 Mar 16. Available from: https://www.bbc.com/news/av/world-51916707

Page 38 
6. Rapi GEN INC. BIOCREDIT COVID COVID-19 Rapid Diagnostic Test. 2020. Apr 10. Available at: https://cdn.website-editor.net/566f06cb b5114499a7ea46cc45686544/files/uploaded/4.\%2520The\%2520rea son $\% 2520$ why\%2520MARKET\%2520wants\%2520BIOCREDIT\%2520C ovid-19\%2520Detection\%2520Kits.pdf

7. Dinnes J, Deeks JJ, Adriano A, Berhane S, Davenport C, Dittrich S, et al. Rapid, point-of-care antigen and molecular-based tests for diagnosis of SARS-CoV-2 infection. The Cochrane database of systematic reviews. 2020;8:Cd013705.

8. Watson J, Whiting PF, Brush JE. Interpreting a covid-19 test result. BMJ. 2020;369:m1808.

9. Usher-Smith JA, Sharp SJ, Griffin SJ. The spectrum effect in tests for risk prediction, screening, and diagnosis. BMJ. 2016;353:i3139.

10. Bruning $A H L$, Leeflang MMG, Vos J, Spijker R, de Jong MD, Wolthers KC, et al. Rapid Tests for Influenza, Respiratory Syncytial Virus, and Other Respiratory Viruses: A Systematic Review and Meta-analysis. Clin Infect Dis. 2017;65(6):1026-32.

11. Wang W, Xu Y, Gao R, Lu R, Han K, Wu G, et al. Detection of SARS-CoV-2 in Different Types of Clinical Specimens. JAMA. 2020;323(18):1843-4.

12. Diao B, Wen K, Chen J, Liu Y, Yuan Z, Han C, et al. Diagnosis of Acute Respiratory Syndrome Coronavirus 2 Infection by Detection of Nucleocapsid Protein. medRxiv. 2020:2020.03.07.20032524.[FullText]

13. Porte L, Legarraga P, Vollrath V, Aguilera X, Munita JM, Araos R, et al. Evaluation of a novel antigen-based rapid detection test for the diagnosis of SARS-CoV-2 in respiratory samples. International Journal of Infectious Diseases. 2020;99:328-33.

14. Mertens P, De Vos N, Martiny D, Jassoy C, Mirazimi A, Cuypers L, et al. Development and Potential Usefulness of the COVID-19 Ag RespiStrip Diagnostic Assay in a Pandemic Context. Frontiers in Medicine. 2020;7:225.

15. Vogels CBF, Brito AF, Wyllie AL, Fauver JR, Ott IM, Kalinich CC, et al. Analytical sensitivity and efficiency comparisons of SARS-COV-2 qRTPCR primer-probe sets. medRxiv. 2020:2020.03.30.20048108.

16. Chan JF-W, Yip CC-Y, To KK-W, Tang TH-C, Wong SC-Y, Leung K-H, et al. Improved Molecular Diagnosis of COVID-19 by the Novel, Highly Sensitive and Specific COVID-19-RdRp/Hel Real-Time Reverse Transcription-PCR Assay Validated \&lt;em\&gt;In Vitro\&lt;/em\&gt; and with Clinical Specimens. Journal of Clinical Microbiology. 2020;58(5):e00310-20.
17. Corman VM, Landt O, Kaiser M, Molenkamp R, Meijer A, Chu DK, et al. Detection of 2019 novel coronavirus (2019-nCoV) by real-time RTPCR. Euro Surveill. 2020;25(3):2000045.

18. Sethuraman N, Jeremiah SS, Ryo A. Interpreting Diagnostic Tests for SARS-CoV-2. JAMA. 2020;323(22):2249-51.

19. Wölfel R, Corman VM, Guggemos W, Seilmaier M, Zange S, Müller $M A$, et al. Virological assessment of hospitalized patients with COVID-2019. Nature. 2020;581(7809):465-9.

20. European Commission. Communication from the Commission: Guidelines on COVID-19 in vitro diagnostic tests and their performance (2020/C 122 I/01). Official Journal of the European Union. $2020 \mathrm{Apr}$ 15. [Internet]. [Cited 19 May 2020]. Available from: https://eur-lex. europa.eu/legal-content/EN/TXT/?uri=CELEX:52020XC0415(04)

21. Gonzalez JM, Shelton JW, Diaz-Vallejo M, Rodriguez-Castellanos VE Zuluaga JDH, Chamorro DF, et al. Immunological assays for SARSCoV-2: an analysis of available commercial tests to measure antigen and antibodies. medRxiv. 2020:2020.04.10.20061150.

22. European Centre for Disease Prevention and Control (ECDC). Coronavirus disease 2019 (COVID-19) in the EU/EEA and the UK ninth update. $2020 \mathrm{Apr} 23$. [Internet]. [Cited 19 May 2020]. Available from: https://www.ecdc.europa.eu/sites/default/files/documents/ covid-19-rapid-risk-assessment-coronavirus-disease-2019-ninthupdate-23-april-2020.pdf

23. Zhang J, Gharizadeh B, Lu D, Yue J, Yu M, Liu Y, et al. Navigating the Pandemic Response Life Cycle: Molecular Diagnostics and Immunoassays in the Context of COVID-19 Management. IEEE Reviews in Biomedical Engineering. 2020;Pp.

24. Gray N, Calleja D, Wimbush A, Miralles-Dolz E, Gray A, De-Angelis $M$, et al. "No test is better than a bad test": Impact of diagnostic uncertainty in mass testing on the spread of COVID-19. medRxiv. 2020.

25. European Centre for Disease Prevention and Control (ECDC). An overview of the rapid test situation for COVID-19 diagnosis in the EU/EEA. 2020 Apr 1. [Internet]. [Cited 19 May 2020]. Available from: https://www.ecdc.europa.eu/en/publications-data/overview-rapidtest-situation-covid-19-diagnosis-eueea

26. World Health Organization (WHO). Medical Product Alert N³/2020 Falsified medical products, including in vitro diagnostics, that claim to prevent, detect, treat or cure COVID-19. $2020 \mathrm{Apr} 5$. Available from: https://www.who.int/news-room/detail/31-03-2020-medicalproduct-alert-n-3-2020 